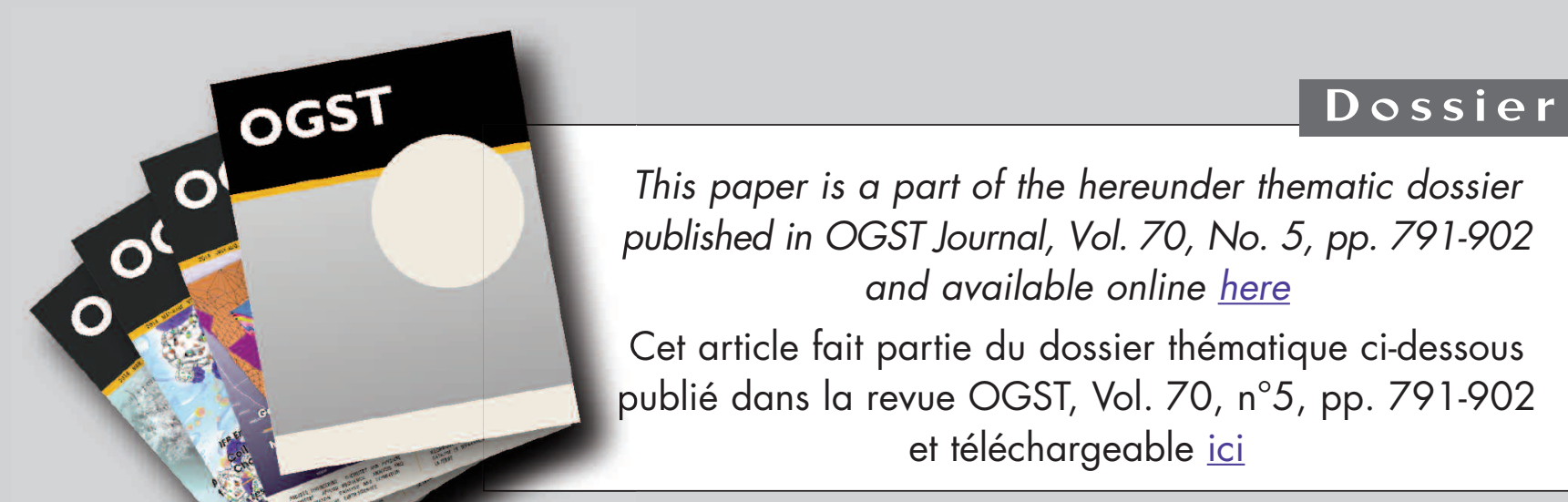

DOSSIER Edited by/Sous la direction de : D. Uzio

IFP Energies nouvelles International Conference / Les Rencontres Scientifiques d'IFP Energies nouvelles

$$
\begin{gathered}
\text { PHOTO4E - Photocatalysis for energy } \\
\text { PHOTO4E - Photocatalyse pour l'énergie }
\end{gathered}
$$

Oil \& Gas Science and Technology - Rev. IFP Energies nouvelles, Vol. 70 (2015), No. 5, pp. 791-902

Copyright (C) 2015, IFP Energies nouvelles

$791>$ Editorial

M. Fontecave, A. Fécant and D. Uzio

$799>$ Solar Production of Fuels from Water and $\mathrm{CO}_{2}$ : Perspectives and Opportunities for a Sustainable Use of Renewable Energy

Production solaire de carburants à partir de l'eau et de $\mathrm{CO}_{2}$ : perspectives et opportunités pour une utilisation durable de l'énergie renouvelable

R. Passalacqua, G. Centi and S. Perathoner

817 > Effect of Post-Synthesis Treatments on the Properties of ZnS Nanoparticles: An Experimental and Computational Study

Effet des traitements après-synthèse sur les propriétés de nanoparticules de ZnS : une étude expérimentale et computationnelle

E. Balantseva, B. Camino, A.M. Ferrari and G. Berlier

831 > Comparative Study on The Photocatalytic Hydrogen Production from Methanol over $\mathrm{Cu}_{-}, \mathrm{Pd}$-, Co- and Au-Loaded TiO

Étude comparative de production d'hydrogène par photocatalyse à partir de méthanol et à l'aide de différentes phases actives ( $\mathrm{Cu}, \mathrm{Pd}, \mathrm{Co}$ et Au) supportées sur TiO

P.P.C. Udani and M. Rønning

841 > Photocatalytic Conversion of Carbon Dioxide Using Zn-Cu-Ga Layered Double Hydroxides Assembled with Cu Phthalocyanine: Cu in Contact with Gaseous Reactant is Needed for Methanol Generation

Conversion photocatalytique du dioxyde de carbone par des hydroxydes doubles lamellaires de Zn-Cu-Ga promus par la phtalocyanine de Cu : nécessité du contact entre le Cu et le réactif gazeux pour la synthèse du méthanol

S. Kawamura, N. Ahmed, G. Carja and Y. Izumi
$853>$ Recyclable PhotoFuel Cell for Use of Acidic Water as a Medium Cellule photocombustible recyclable pour I'utilisation d'eau acide en tant que milieu

Y. Ogura, M. Yoshiba, and Y. Izumi

$863>$ Solar Hydrogen Reaching Maturity L'hydrogène solaire arrive à maturité

J. Rongé, T. Bosserez, L. Huguenin, M. Dumortier, S. Haussener and J.A. Martens

877 > Design of Compact Photoelectrochemical Cells for Water Splititing Conception de cellules photoélectrochimiques compactes pour la décomposition de l'eau

T. Bosserez, J. Rongé, J. van Humbeeck, S. Haussener and J. Martens

891 > Simultaneous Production of $\mathrm{CH}_{4}$ and $\mathrm{H}_{2}$ from Photocatalytic Reforming of Glucose Aqueous Solution on Sulfated Pd-TiO, Catalysts Production simultanée de $\mathrm{CH}_{4}$ et $\mathrm{H}_{2}$ par réformage photocatalytique d'une solution aqueuse de glucose sur un catalyseur Pd-TiO, sulfaté V. Vaiano, G. lervolino, G. Sarno, D. Sannino, L. Rizzo, J.J. Murcia Mesa, M.C. Hidalgo and J.A. Navío 


\title{
Effect of Post-Synthesis Treatments on the Properties of ZnS Nanoparticles: An Experimental and Computational Study
}

\author{
Elena Balantseva ${ }^{1 *}$, Bruno Camino², Anna Maria Ferrari ${ }^{1}$ and Gloria Berlier ${ }^{1 *}$ \\ ${ }^{1}$ Università di Torino, Dipartimento di Chimica and NIS (Nanostructured Interfaces and Surfaces) Centre, Via P. Giuria 7, 10125 Torino - Italy \\ 2 Department of Chemistry, Imperial College London, South Kensington London SW7 2AZ - United Kingdom \\ e-mail: ebalants@gmail.com-gloria.berlier@unito.it \\ * Corresponding authors
}

\begin{abstract}
This work deals with the characterization of ZnS NanoParticles (NP), prepared by precipitation employing thioacetamide as sulfur source at different reaction time length. The attention is focused on the modification induced on structural, surface and electronic properties of $\mathrm{ZnS} N P$ by post-synthesis treatments. These were aimed at removing from the samples surface adsorbed reactants, by washing or thermal treatments, both in air or vacuum. The effect of these parameters is followed by X-Ray Diffraction (XRD), Transmission Electron Microscopy (TEM), Fourier Transform InfraRed (FTIR), gas-volumetric and ThermoGravimetric Analysis (TGA). Moreover, the effect of nanostructuration on the semiconducting material band gap is evaluated by Diffuse Reflectance UV-Vis (DR UV-Vis) spectroscopy. Density Functional Theory (DFT) calculations have been employed to clarify the role of the adsorbed reactants on the surface stability and to assess the relationship between particle size and band gap value.
\end{abstract}

Résumé - Effet des traitements après-synthèse sur les propriétés de nanoparticules de ZnS : une étude expérimentale et computationnelle - Ce travail concerne la caractérisation de nanoparticules de ZnS préparées par précipitation en présence de ThioAcétAmide (TAA) comme source de soufre. On a étudié, en particulier, les modifications des propriétés structurelles, superficielles et électroniques en fonction des paramètres de synthèse (temps, solvant et source de soufre) et des traitements aprèssynthèse considérés. Ces derniers avaient pour but d'éliminer les réactifs adsorbés sur la surface par lavages ou traitements thermiques à l'air ou sous vide. L'effet des différents traitements a été suivi par diffraction des rayons X (XRD), microscopie de transmission électronique (TEM), spectroscopie infra rouge à transformée de Fourier (FTIR), analyse volumétrique des gaz et thermogravimétrie (TGA). En outre, l'effet de la nanostructure sur les propriétés de la largeur de bande du matériau semi-conducteur a été évalué par spectroscopie de reflectance UV-Vis (DR UV-Vis). Des théories de la fonctionnelle de la densité (DFT) ont été utilisées pour clarifier le rôle des réactifs adsorbés sur la stabilité de la surface et pour établir une relation entre la dimension des particules et la largeur de bande. 


\section{INTRODUCTION}

Since the first discovery by Honda and Fujishima, photocatalyst hydrogen production has attracted strong consideration [1]. Many heterogeneous photocatalysts have been found, mostly working in ultraviolet region, which accounts for only 5\% of the solar spectrum [2-4]. Taking this into account, it is understandable the existing wide interest in searching new visible-light-driven photocatalysts that could replace the "old" ones and extend their response to the solar spectrum. Up to now, the number of such photocatalysts is still limited [5-7]. Although CdS is reported as an effective photocatalyst with a bang gap suitable for visible light exploitation, its activity depends on expensive noble metals deposited on its surface, and environmental and safety concerns related to the well-know cadmium toxicity are serious limitations to applications in large scale $[8,9]$. As an alternative $\mathrm{ZnS}$ can produce $\mathrm{H}_{2}$ effectively without noble metal co-catalyst, due to its high conduction band position, but the wide band gap $(3.7 \mathrm{eV})$ implies that only ultraviolet radiation can be employed to produce electron/hole couples [10]. This is the reason why band gap engineering has been proposed to modify the electronic properties of $\mathrm{ZnS}$ and improve its visible light harvesting efficacy [11-13].

Apart from the electronic properties (band gap, conduction and valence band position) the main requirements for an efficient photocatalysts are high crystallinity (to avoid the presence of defects, acting as electron/hole recombination traps), coupled to high surface area and small particle size (to increase the efficacy of electron/hole migration to the surface). This implies that a careful control of these parameters is crucial in the synthesis of a nanostructured photocatalyst.

Different chemical routes have been used to prepare small semiconducting NanoParticles (NP). The most common way is to use stabilizing agents which prevent growth of particles and their agglomeration by electrostatic and steric repulsion [14-19]. But at the same time they modify the structural, morphological and optical properties of nanoparticles. Growth of strongly confined nanoparticles without a capping agent is difficult to achieve and rarely reported. Among other chemical routes the use of reversed micellars solutions $[20,21]$, thin film deposition process, inorganic templates were reported.

For materials based on $\mathrm{CdS}$ and $\mathrm{ZnS}$ an alternative route for preparation of nanoparticles is a hydrothermal synthesis procedure [22]. The use of ThioAcetAmide (TAA) as a sulfur source allows obtaining well mono-dispersed particles, whose size depends upon the reaction conditions. The formation of small spherical CdS NP, which are then transformed into cylindrical structures while the reaction proceeds was reported [23]. The early work where TAA was applied in $\mathrm{ZnS}$ synthesis reported the formation of submicrometric particles [24]. Later, the effect of sulfur source (TAA in comparison with $\mathrm{Na}_{2} \mathrm{~S}$ ) in the synthesis of $\mathrm{ZnS}$ based system $(\mathrm{ZnS} / \mathrm{CdS}, \mathrm{ZnS} / \mathrm{ZnO})$ was studied by different authors $[25,26]$. The detailed investigation of the precipitation dynamic of $\mathrm{ZnS}$ from TAA decomposition in conditions close to those applied in other works was carried out with attention on product agglomeration [27]. The authors showed a crucial role of hydrodynamics in the determination of size and agglomeration, and studied the influence of parameters such as $\mathrm{pH}$, electrical conductivity, concentration of sulfide ions and turbidity. The obtained results could be very helpful in control of morphology and associated properties.

Recently, we also demonstrated that this synthesis procedure works well in case of $\mathrm{ZnS}$ [28]. In particular, we showed that the reaction carried out at room temperature employing a methanol/ethanol mixture as a solvent was suitable for the formation of small $\mathrm{ZnS} \mathrm{NP}$ with much higher yield with respect to what obtained in water. In this contribution, the attention is focused on the effect of post-synthesis treatments, aimed at removing the reactants and impurities adsorbed on the $\mathrm{ZnS}$ photocatalyst surface, on the material properties. This is studied on samples prepared at different reaction time length in methanol/ethanol mixture with TAA. The work reports a detailed physico-chemical characterization of the materials, concerning their morphology, structure, textural properties, adsorbed species and electronic properties. Moreover, Density Functional Theory (DFT) calculations have been employed to gain hints on the size dependence of surface and electron properties of the $\mathrm{ZnS}$ NP. The adsorption of formic acid (as a simple model of surface species adsorbed during the synthesis process) has been simulated. The interaction with the most relevant $\mathrm{ZnS}$ surfaces (110 and 111) [29] has been considered.

\section{EXPERIMENTAL SECTION}

\subsection{Synthesis}

ThioAcetAmide $\left(\mathrm{CH}_{3} \mathrm{CSNH}_{2}\right.$, TAA) was purchased from Sigma Aldrich; analytical grade zinc acetate ( $\mathrm{Zn}$ $\left.\left(\mathrm{CH}_{3} \mathrm{COO}\right)_{2} \cdot 2 \mathrm{H}_{2} \mathrm{O}, \mathrm{ZnAc}\right)$ from Baker Analyzed ACS Reagent; methanol and ethanol from Carlo Erba reagents. Bulk ZnS (powder, $<10 \mu \mathrm{m}, 99.99 \%$ ) was purchased from Sigma Aldrich. All the chemical and solvents were used as received without further purification.

In a typical procedure TAA and ZnAc were dissolved separately in ethanol/methanol $1 / 1$ mixture at $313 \mathrm{~K}$, to give $0.2 \mathrm{M}$ solutions $[28,29]$. The TAA solution was then slowly added to the $\mathrm{ZnAc}$ one under continuous stirring. The resulting mixture ( $50 \mathrm{~mL}$ total volume) was left under stirring for $6 \mathrm{~h}$ or $24 \mathrm{~h}$. Afterwards the resulting white powder was 
separated by centrifugation (4 $000 \mathrm{rpm}$ ), and washed first with the alcohol mixture and then trice with distilled water at Room Temperature (RT) or $353 \mathrm{~K}$. The cleaned product was dried for about $3 \mathrm{~h}$ in oven at $353 \mathrm{~K}$. The obtained samples were carefully milled before characterization. The labeling of the samples in the text is related to reaction time length (ZnS_6h or ZnS_24h) and to the water temperature in washing procedure: $\mathrm{ZnS} \_x \mathrm{~h} \_\mathrm{HW}(x=6$ or 24$)$ are the samples treated with hot water. The same synthetic procedure was carried out at 6 hours reaction by employing $\mathrm{Na}_{2} \mathrm{~S}$ as sulfur source instead of TAA (sample $\mathrm{ZnS} \mathrm{Na}_{2} \mathrm{~S}$ ). This resulted in a much lower yield, so that these results are only reported for comparison.

Thermal activation in oven or in vacuum was carried out on sample ZnS_6h_HW. The resulting samples are labeled mentioning the activation temperature and conditions (ZnS_573 activated in oven at $573 \mathrm{~K}$, sample ZnS_673_V activated at $673 \mathrm{~K}$ in vacuum).

\subsection{Characterization}

Powder X-Ray Diffraction (XRD) patterns were measured with PW3050/60 X'Pert PRO MPD diffractometer (Panalytical) working in Bragg-Brentano geometry using $\mathrm{Cu} \mathrm{K \alpha}$ radiation $(\lambda=1.5406 \AA)$ and operated at $45 \mathrm{kV}, 40 \mathrm{~mA}$ with a scan speed of $0.01^{\circ} \mathrm{min}^{-1}$ and step size of $0.0170^{\circ}$. The crystallite size $D=4 / 3 \mathrm{~L}$ was calculated by applying the Scherrer's equation to the (111) peak at $28.7^{\circ}$ :

$$
L=k \lambda /(\beta \cos \theta)
$$

where $\lambda$ is the $\mathrm{X}$-ray wavelength, $\beta$ the measured broadening of the diffraction peak and $\theta$ the diffraction angle [30]. The measured $\beta$ value was corrected by subtracting the instrumental line broadening, estimated in $0.02^{\circ}$. The error on particle size estimation was calculated by including standard deviation on 5 measurements and instrumental resolution.

Transmission Electron Microscopy (HRTEM) measurements were performed on JEM 3010-UHR microscope (JEOL Ltd.) operating at $300 \mathrm{kV}$. For the measurements $\mathrm{ZnS}$ powder was dispersed on a copper grid coated with a perforated carbon film.

Gasvolumetric nitrogen adsorption/desorption isotherms were measured at Liquid Nitrogen Temperature (LNT) with ASAP 2020 physisorption analyzer (Micromeritics). Prior to analyses, samples were evacuated at $423 \mathrm{~K}$ over $2 \mathrm{~h}$. The Specific Surface Area (SSA) was calculated by the Brunauer-Emmett-Teller (BET) method in the $p / p_{0}$ range from 0.05 to 0.2 [31]. The average pore size and volume were calculated on the adsorption branch of the isotherms according to the Barrett-Joyner-Halenda (BJH) method [32, 33].
ThermoGravimetric Analysis (TGA) was carried out on a TAQ600 (TA Instruments) heating the samples at a rate of $10 \mathrm{~K} \mathrm{~min}^{-1}$ from 303 to $1123 \mathrm{~K}$ in air flow. Before starting the measurements, samples were equilibrated at $303 \mathrm{~K}$.

Fourier Transform InfraRed (FTIR) spectra were recorded with an IFS66 spectrophotometer (Bruker) equipped with a Deuterated TriGlycine Sulfate (DTGS) detector, working with resolution of $4 \mathrm{~cm}^{-1}$ over 32 scans. Samples were in the form of self-supporting pellets suitable for transmission infrared experiments and were placed in a quartz cell equipped with $\mathrm{KBr}$ windows, designed for in situ studies in vacuum and controlled atmosphere. Before infrared analysis the samples were evacuated at the desired temperature (RT or $673 \mathrm{~K}$ ) for 1 hour.

Diffuse Reflectance (DR) UV-Vis measurements were recorded on powdered samples on a Cary 5000 spectrophotometer equipped with a reflectance sphere. Spectra were recorded at a scan rate of $300 \mathrm{~nm} / \mathrm{min}$ with a step size of $1 \mathrm{~nm}$ and fixed Spectral Band Width (SBW) of $2 \mathrm{~nm}$. The measured intensities were converted with the Kubelka-Munk function. The fundamental absorption, which corresponds to electron excitation from the valance band to conduction band, can be used to determine the value of the optical band gap of the synthesized $\mathrm{ZnS}$ nanoparticles [34-37]. The relation between the incident photon energy $(h v)$ and the absorption coefficient $(\alpha)$ is given by the following relation: $(\alpha h v)^{1 / n}=A\left(h v-E_{g}\right)$, where $A$ is constant and $E_{g}$ is the band gap energy of the material and the exponent $n$ depends on the type of transition [38, 39]. $\mathrm{ZnS}$ as a semiconductor is characterized by direct allowed transition where $n=1 / 2$ [40], therefore the direct band gaps of the samples are calculated by plotting $(\alpha h v)^{2}$ versus $h v$ and then extrapolating the straight portion of the curve on $h v$ axis at $\alpha=0$.

\subsection{DFT Modeling}

Results presented are obtained with periodic CRYSTAL09 code [41], using the hybrids B3PW (the combination of the Becke's three parameter functional [42] for the exchange and the Perdew Wang functional [43] for the correlation) and PBE0 [44]. Basis sets of triple-zed TZ quality for the valence electrons have been employed: the relativistic Steven-Krauss small core RECP with a 4211-41 [4sp2d] basis set for valence electrons for $\mathrm{Zn}$ atoms [45] combined to a 8-6311-1 [1s-4sp-1d] for S [45]. Within this computational set up, B3PE has been found to provide accurate estimate of the $\mathrm{ZnS}$ band gap $\left(E_{g}=3.71 \mathrm{eV}\right)$ very close to the experimental value $\left(E_{g}=3.65-3.7 \mathrm{eV}\right)$, while PBE0 was found to accurately accounts for surface properties [29, 46, 47].

In the CRYSTAL code, the level of accuracy in evaluating the Coulomb and the exchange series is controlled by five 
parameters [41] for which $10^{-7}, 10^{-7}, 10^{-7}, 10^{-7}, 10^{-18}$ values have been used for all calculations. The convergence threshold for SCF energy was set to $10^{-9} \mathrm{Ha}$. The reciprocal space was sampled according to a regular sublattice determined by the shrinking factor IS [41]. A value of IS $=8$ has been adopted which corresponds to 34 independent $k$-points in the irreducible part of the Brillouin zone.

Nanoparticles have been modeled with bidimensional slabs of increasing thickness $d$ (from 0.5 to about $6 \mathrm{~nm}$ ), characterized by two infinite dimensions $(x, y)$ and a finite thickness, and cut from the bulk so as to expose the most stable $\mathrm{ZnS}$ surface, the (110) [29]. Stoichiometric ZnS slabs $(\mathrm{Zn} / \mathrm{S}$ ratio equal to $1 / 1)$ have been considered, in agreement with the experimental and theoretical reports [28, 48-51]. Surface Energy $\left(E_{s}\right)$ is calculated as: $E_{s}=\frac{E_{\text {slab }}-n E_{\text {bulk }}}{2 A}$ where $E_{\text {slab }}$ is the energy of an $n$-layered 2D slab used to model the material that exposes the surface of interest, $E_{\text {bulk }}$ is the energy of the bulk material and $A$ is the area of the 2D surface cell. The factor $1 / 2$ accounts for the existence of two limiting surfaces. $E_{s}$ is then the energy per unit area required to form the surface from the bulk and it is reported in $\mathrm{J} / \mathrm{m}^{2}$.

The interaction with formic acid has been computed considering a coverage $(\theta=0.5$ (simulated adopting a $2 \times 1$ supercell). Slabs of thickness of 1.2 and $1.5 \mathrm{~nm}$ have been selected for the (110) and (111) surfaces (corresponding to 7 and $6 \mathrm{ZnS}$ layers, respectively). The Adsorption Energy $\left(\Delta E_{a d s}\right)$ per molecule is calculated as: $E_{a d s}=\frac{E_{a}-n E_{m}-E_{s l a b}}{n}$, where $E_{m}$ is the energy of the optimized isolated molecule, $E_{\text {slab }}$ is the energy of the optimized isolated slab modeling the surface and $n$ is the number of molecules per cell. The basis set superposition error BSSE has been estimated, by employing the counterpoise method [52], to account for no more than $0.07 \mathrm{eV}$ and results are corrected accordingly.

For all the systems discussed in this study, geometry has been optimized relaxing all the atoms in the cell and keeping fixed the lattice parameters at the bulk values. All the symmetry constraints have been removed. Adsorbate frequencies have been computed at the $\Gamma$ point, within the harmonic approximation, by diagonalizing the massweighted Hessian matrix only for the adsorbate fragment, once checked that its vibrational modes are not coupled with other crystal phonons.

\section{RESULTS AND DISCUSSION}

\subsection{Effect of Synthesis and Post-Synthesis Conditions on Crystallite Size and Textural Properties}

The general properties of the prepared samples are listed in Table 1, with those of ZnS_bulk (commercial sample) for comparison. These include the crystallite size calculated
TABLE 1

General properties of the $\mathrm{ZnS}$ samples depending on condition of synthesis and purification

\begin{tabular}{c|c|c|c|c}
\hline Samples & $\begin{array}{c}\text { Crystallite } \\
\text { size }(\mathrm{nm}) \\
\mathrm{XRD}^{\mathrm{a}}\end{array}$ & $\begin{array}{c}\mathrm{SSA}^{\mathrm{b}} \\
\left(\mathrm{m}^{2} / \mathrm{g}\right)\end{array}$ & $\begin{array}{c}\text { Pore } \\
\text { volume } \\
\left(\mathrm{cm}^{3} / \mathrm{g}\right)^{\mathrm{c}}\end{array}$ & $\begin{array}{c}\text { Band } \\
\text { gap } \\
E_{g}(\mathrm{eV})\end{array}$ \\
\hline ZnS_6h & 1.8 & 294 & 0.12 & 4.22 \\
\hline ZnS_6h_HW & 3.5 & 376 & 0.60 & 3.72 \\
\hline ZnS_24h & 4.1 & 277 & 0.30 & 3.67 \\
\hline ZnS_24h_HW & 3.4 & 184 & 0.30 & 3.59 \\
\hline ZnS_Na2S & 4.9 & 236 & 0.24 & 3.55 \\
\hline ZnS_573 & 3.5 & 108 & 0.28 & 3.44 \\
\hline ZnS_673_V & 3.7 & 123 & 0.25 & 3.22 \\
\hline ZnS_bulk & 33.2 & 24 & 0.07 & 3.60 \\
\hline
\end{tabular}

${ }^{a}$ Calculated with the Scherrer equation, estimated error $\pm 0.017 \mathrm{~nm}$.

b Measured by BET equation.

c Measured by BJH method in the isotherm adsorption branch.

by XRD (Scherrer equation applied to the 111 peak) and the textural properties, that is SSA and pore volume. The reported band gap values were calculated from DR UV-Vis spectra, as discussed in the following (Sect. 2.3).

A selection of XRD patterns of the materials is reported in Figure 1. All synthesized $\mathrm{ZnS}$ samples have three main diffraction peaks at $28.7,47.9$ and $56.8^{\circ}$, corresponding to the (111), (220) and (311) lattice planes of $\mathrm{ZnS}$ cubic sphalerite structure (JCPDS 010772100). Minor features can be observed at $32.9,70.3$ and $77.5^{\circ}$, due to (200), (400) and (331) reflections. Sample ZnS_6h shows quite broad peaks, corresponding to an average crystallite size (Scherrer equation) of $1.8 \mathrm{~nm}$. The peak width decreases both in relation to longer reaction time $(\mathrm{ZnS} 24 \mathrm{~h})$ and after washing with hot water. On the contrary, hot washing did not particularly affect the XRD patterns and related crystallite size of sample $\mathrm{ZnS} 24 \mathrm{~h}$.

The estimated crystallite size of all samples is listed in Table 1. The smallest crystallite size was obtained for $\mathrm{ZnS}$ _6h. Changing all other parameters leads to slight growing of particles. Moreover the use of $\mathrm{Na}_{2} \mathrm{~S}$ as sulfur source instead of TAA resulted in relatively big particles. As mentioned in the experimental section, this procedure gives a very low yield, and is only reported for comparison.

The changes in SSA and porosity of the samples as a function of synthesis parameters are not directly correlated to the crystallite size estimated by XRD. For instance, washing with hot water causes an increase in SSA and pore volume in sample $\mathrm{ZnS}$-6h. This could be easily explained by considering that the samples porosity is due 


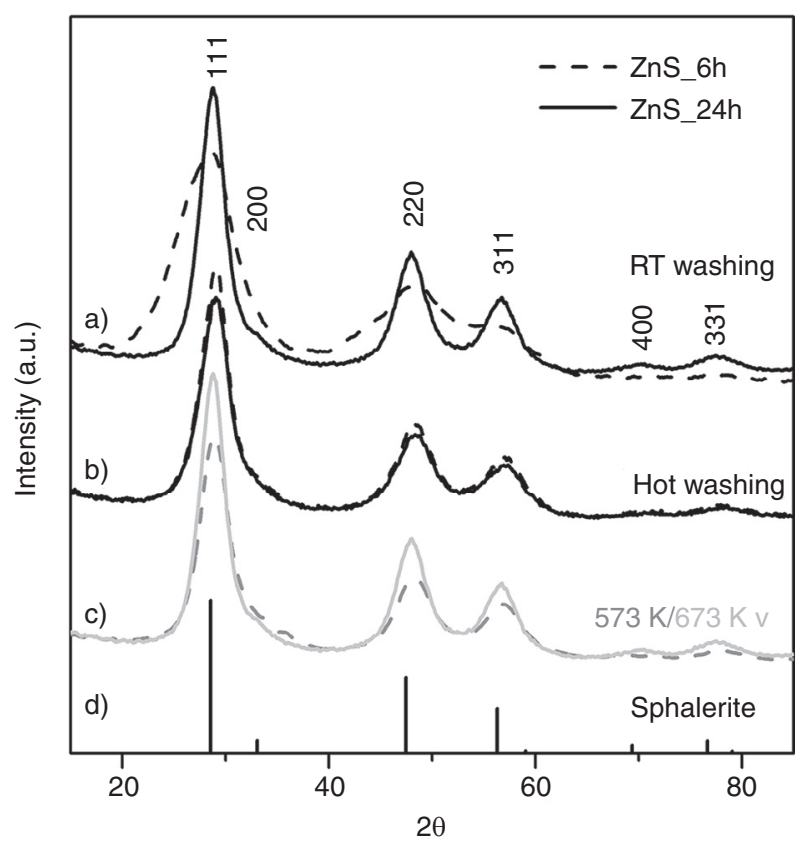

Figure 1

$\mathrm{XRD}$ patterns of $\mathrm{ZnS}$ particles as a function of different preparation conditions: a) as prepared (simply washed at RT); b) washed with hot water; c) treated in oven at $573 \mathrm{~K}$ or in vacuum at $673 \mathrm{~K}$; d) cubic ZnS (sphalerite, JCPDS 010772100). Curves were vertically shifted for easier comparison.

to interparticle voids [29]: the removal of adsorbed products from the sample surface by hot washing increases the accessible volume and surface area of the particles. However, the same effect is not evident in sample ZnS_24h, where washing causes a slight decrease in both crystallite size and SSA. On the whole, all prepared samples show relatively high SSA, which represents an important point for application in photocatalysis.

The prepared samples were also subjected to thermal treatments, as an alternative way (often employed in catalysis) to remove adsorbed impurities and obtain a clean surface. The effect of thermal treatments in vacuum was already described in Reference [29], by employing both XRD and TEM techniques. As reported elsewhere, thermal treatments in air of $\mathrm{ZnS}$ causes the transformation to $\mathrm{ZnO}$ [53-55]. This was confirmed on our samples by both activation in static oven and in $\mathrm{N}_{2} / \mathrm{O}_{2}$ flow. In both cases, the transformation to $\mathrm{ZnO}$ started around $673 \mathrm{~K}$ (data not reported), while after activation at $573 \mathrm{~K}$ only the typical XRD peaks of cubic $\mathrm{ZnS}$ were observed (Fig. 1, grey dashed curve c). This pattern is compared in the same figure with that obtained after activation in vacuum at $673 \mathrm{~K}$ [29]. The crystallite size of both samples is similar to what measured before thermal activation (Tab. 1), but a decrease in SSA and pore volume is observed, suggesting further agglomeration of the primary $\mathrm{ZnS}$ NP.

TEM micrographs of the prepared $\mathrm{ZnS}$ samples revealed the presence of dense agglomerates of spheroidal particles (Fig. 2). It is however possible to observe light regions among the particles, which could be related to interparticle voids resulting in high surface area and pore volume. The high agglomeration of the material did not allow obtaining high resolution images of single particles, so that a reliable particle size analysis was not possible. The average value of $c a .2 .6( \pm 0.4) \mathrm{nm}$ (measured on 20-50 particles) was found for the sample $\mathrm{ZnS} 6 \mathrm{~h}$, in good agreement with $\mathrm{XRD}$. It is important to underline the fact that the changes in crystalline domains size estimated by XRD cannot be appreciated by TEM, since the micrographs of samples ZnS_6h_HW are hardly distinguishable from those of ZnS_6h (Fig. 2, compare top panels with the left bottom one). In the case of sample ZnS_24h, the particles look more defined and crystallized with respect to the former (right bottom panel of Fig. 2). Particle size analysis was almost impossible in this case, due to very dense agglomeration of the primary particles, which however showed a primary size around $2-3 \mathrm{~nm}$, which is similar to that of $\mathrm{ZnS} \_6 \mathrm{~h}$. The different size estimated by XRD can thus be explained on the basis of higher crystallinity (less defective surfaces) and/or more dense aggregation.

Lattice fringes are visible in the TEM micrograph (bottom right panel of Fig. 2), indicating the crystalline nature of the particles. Fourier Transform (FT) analysis of the images resulted in a diffraction ring with average $d$-spacing of $3.0 \AA$, characteristic of the (111) peak of ZnS cubic structure.

On the whole, the results discussed in this paragraph suggest that the particles obtained at $6 \mathrm{~h}$ synthesis are stabilized by adsorbed reactants, so that hot washing causes a partial aggregation of the primary particles. At longer reaction time length, more crystalline domains are formed, which are densely interconnected, as shown by both TEM and surface area analysis. In this case, the role of adsorbed species in stabilizing the particles is less important.

\subsection{Surface Adsorbed Species}

\subsubsection{Quantitative Analysis}

The nature and amount of species adsorbed on the surface of the prepared $\mathrm{ZnS}$ sample was studied by thermogravimetric analysis. To this aim, the attention was focused on sample $\mathrm{ZnS}$ 6h and following modifications (ZnS_6h_HW, ZnS_573 and ZnS_673_V). These are reported in Figure 3 together the results obtained on $\mathrm{ZnS} \_\mathrm{Na}_{2} \mathrm{~S}$ for comparison. All experiments were carried out in air flow, and an analysis on $\mathrm{ZnS} \_6 \mathrm{~h}$ was repeated in nitrogen. 

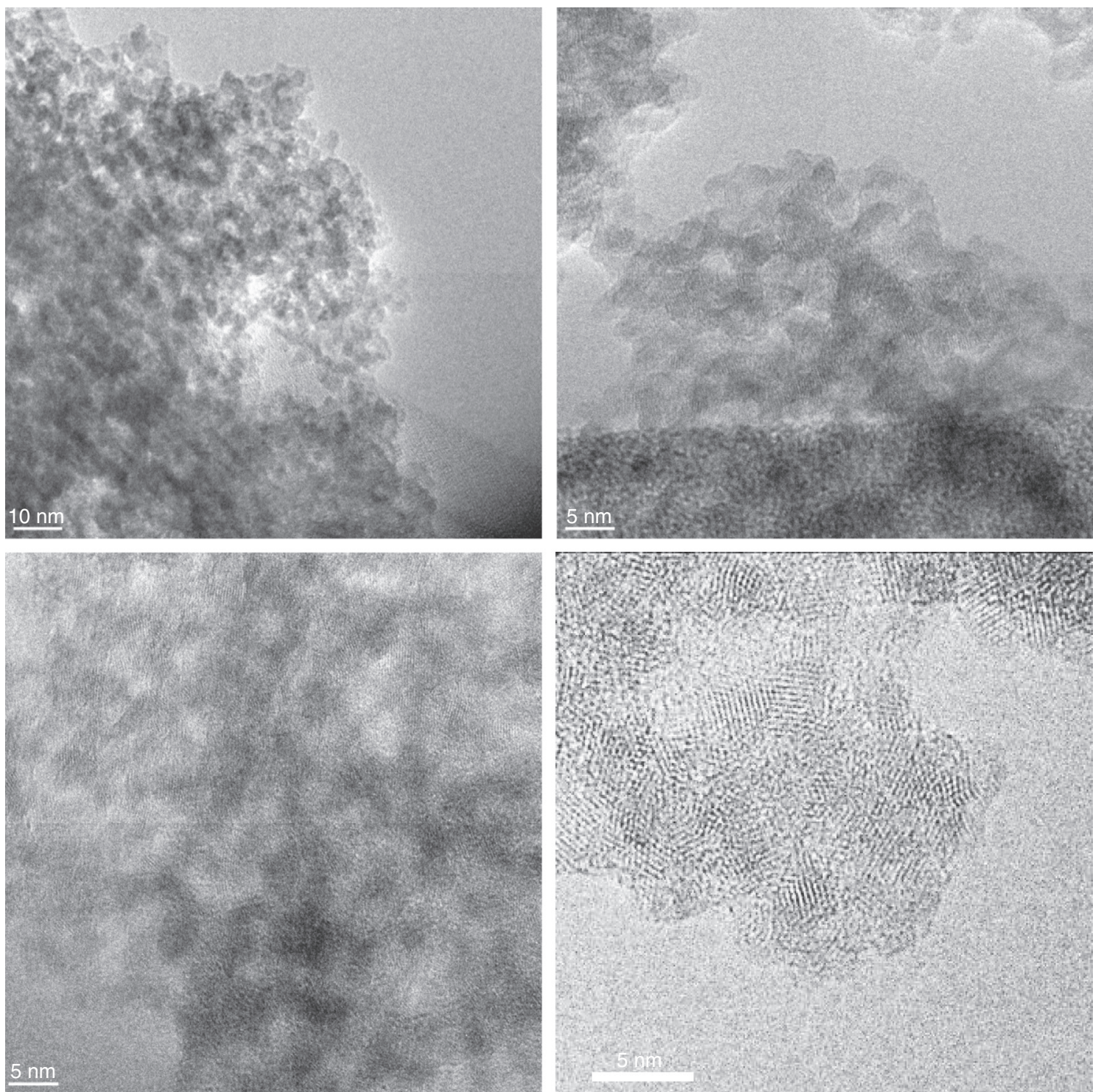

Figure 2

Representative HRTEM images of: (top) ZnS_6h (left 250000X and right 400000X; (bottom) ZnS_6h_HW and ZnS_24h (left and right respectively, both measured at $400000 \mathrm{X}$ ).

The TG curve of ZnS_6h is characterized by three distinct steps of weight loss accompanied by definite peaks on the Differential Thermal Analysis (DTA) curve (not shown). The first minor weight loss $(4.2 \%)$ is centered around $363 \mathrm{~K}$ and corresponds to desorption of water molecules weakly bonded to the surface. The next two steps with larger weight losses started around $473 \mathrm{~K}$ (maximum of DTA at $620 \mathrm{~K}$ ) and $773 \mathrm{~K}$ (DTA maximum around $830-850 \mathrm{~K}$ ). To understand the nature of these steps it is useful to compare the profiles of the different samples and corresponding amounts listed in Table 2.
First, the amount of adsorbed water slightly changes upon synthesis and treatment conditions, in a range from 1.3 to $6.6 \%$. This could suggest an effect of treatments or reactants on surface hydrophilicity. For instance the highest amount is observed on samples washed with hot water (ZnS_6h_HW) and prepared with $\mathrm{Na}_{2} \mathrm{~S}$. This could be related to the fact that the surface of these samples is less covered by reactants and it is thus more available to water interaction.

This hypothesis is confirmed by comparing the TG profiles of $\mathrm{ZnS} \_6 \mathrm{~h}, \mathrm{ZnS} \_\mathrm{Na}_{2} \mathrm{~S}$ and $\mathrm{ZnS} \_6 \mathrm{~h} \_\mathrm{HW}$. The first looses $18 \mathrm{wt} \%$ in step II, while this is reduced to $2.1 \%$ in 


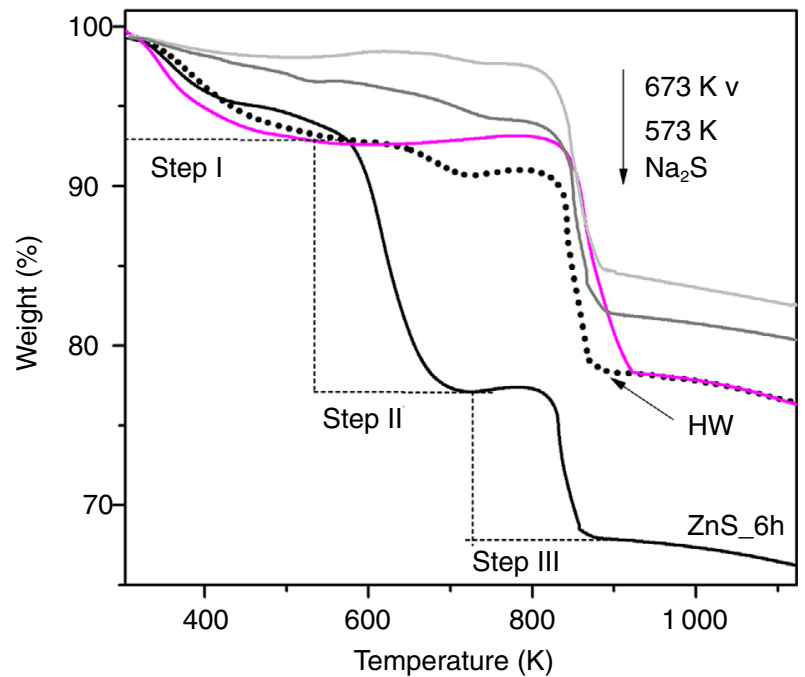

Figure 3

TGA curves of $\mathrm{ZnS} \_6 \mathrm{~h}$, as such and after different treatments. Results about $\mathrm{ZnS}_{-} \mathrm{Na}_{2} \mathrm{~S}$ are reported for comparison.

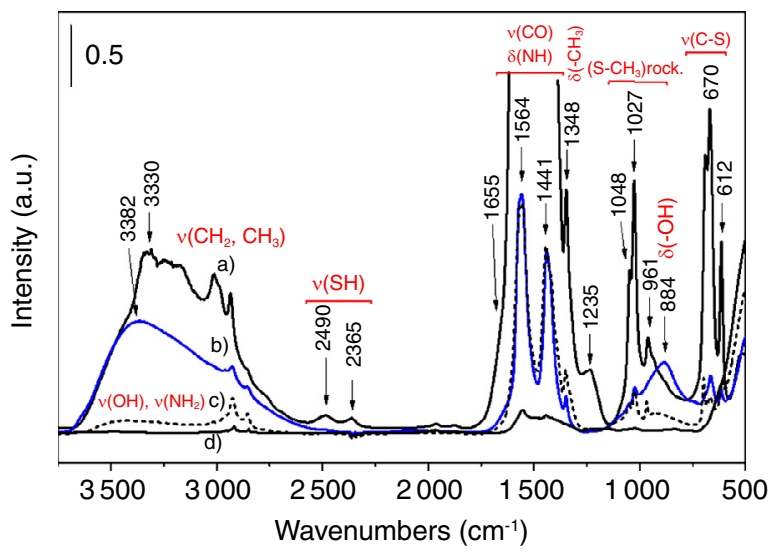

Figure 4

FTIR spectra of ZnS_6h sample as such a) and after postsynthesis treatments: b) ZnS_6h_HW; c) ZnS_573 and d) ZnS_673_V. All samples were outgassed at RT before measurements, expected ZnS_673_V which was outgassed at $673 \mathrm{~K}$.

ZnS_6h_HW and to practically zero in $\mathrm{ZnS} \_\mathrm{Na}_{2} \mathrm{~S}$. This clearly indicates that hot water treatment removes weakly adsorbed reactants from the synthesis, in particular TAA, which was not employed to prepare $\mathrm{ZnS} \_\mathrm{Na}_{2} \mathrm{~S}$. Noticeably, a small amount of adsorbed species is still present after hot washing, thermal activation at $573 \mathrm{~K}$ in air or $673 \mathrm{~K}$ in vacuum (2.4 and $0.4 \mathrm{wt} \%$, respectively). In this case, the desorption starts at higher temperature (533-593 K) with respect to untreated sample ( $453 \mathrm{~K}$ ) indicating a stronger interaction of the related adsorbed species. These are explained as residual
TABLE 2

Data from thermogravimetric analysis (percentage weight loss) of $\mathrm{ZnS}$ 6 $6 \mathrm{~h}$ as such and after post-synthesis treatments. Data about $\mathrm{ZnS} \mathrm{Na}_{2} \mathrm{~S}$ are reported for comparison

\begin{tabular}{c|c|c|c}
\hline Samples & Step I & Step II & Step III \\
\hline ZnS_6h & 4.2 & 18.0 & 9.3 \\
\hline ZnS_6h ( N $)^{*}$ & 4.2 & 20.1 & 0 \\
\hline ZnS_6h_HW & 6.6 & 2.1 & 12.4 \\
\hline ZnS_573 & 2.8 & 2.4 & 12.3 \\
\hline ZnS_673_V & 1.3 & 0.4 & 15.4 \\
\hline ZnS_Na $2 S$ & 6.6 & 0 & 14.5 \\
\hline
\end{tabular}

${ }^{*}$ Experiment carried out in nitrogen flow instead of air.

acetate groups from the synthesis, as will be discussed in the following.

Finally, step III is similar in all samples, but is not observed when the analysis is carried out in nitrogen (curve not reported, data summarized in Tab. 2). This obviously allows assigning this phenomenon to an oxidative process, that is the transformation of $\mathrm{ZnS}$ to $\mathrm{ZnO}$, which in these conditions starts above $800 \mathrm{~K}$ irrespective of the samples synthesis or treatment, in agreement with XRD findings (not reported).

\subsubsection{Infrared Spectroscopy (FTIR)}

The nature of adsorbed species was also studied by infrared spectroscopy, again focusing on sample $\mathrm{ZnS} 6 \mathrm{~h}$ and its transformation upon post-synthesis treatments (Fig. 4). The as prepared sample (curve a) shows very intense bands in the whole mid infrared region, which can be easily assigned to adsorbed species, reactants or contaminants from the atmosphere. We observed a broad absorption in the $\mathrm{OH}$ stretching region $(\mathrm{vOH})$ between 3600 and $2500 \mathrm{~cm}^{-1}$, with superimposed bands between 3000 and $2800 \mathrm{~cm}^{-1}$ related to aliphatic $v \mathrm{CH}_{2}$ and $v \mathrm{CH}_{3}$ modes. At lower frequency, weak bands at 2940 and $2365 \mathrm{~cm}^{-1}$ are assigned to $v \mathrm{~S}-\mathrm{H}$ groups [56]. The more intense spectral features (out of scale) are found in the $1750-1250 \mathrm{~cm}^{-1}$ range, where both $\mathrm{N}-\mathrm{H}$ bending $\left(\delta \mathrm{NH}\right.$, found at $1400 \mathrm{~cm}^{-1}$ for TAA in $\mathrm{KBr}$, spectra not reported) and $v \mathrm{CO}$ modes are found. Other peaks at lower frequency can be assigned to bending modes of $\mathrm{CH}_{3}$ in $\mathrm{CH}_{3}$-S groups, namely symmetric vibrations at 1385 and rocking at $1110 \mathrm{~cm}^{-1}$, and to $v \mathrm{C}-\mathrm{S}$ modes $\left(611 \mathrm{~cm}^{-1}\right)$ as confirmed by comparison with $\mathrm{KBr}$ spectra of TAA (not reported). These bands confirm the presence of TAA molecules adsorbed on the sample surface, which could be present as $\mathrm{CH}_{3}-\mathrm{S}-\mathrm{NH}_{2}$ in tautomeric equilibrium with $\mathrm{CH}_{3}-\mathrm{SH}-\mathrm{NH}$ form [57]. On the contrary, the two strong bands at 1564 and $1441 \mathrm{~cm}^{-1}$ can be ascribed to 
the presence of adsorbed acetate groups from the employed reactants. This hypothesis is supported by comparison with the spectra measured on samples $\mathrm{ZnS} \_\mathrm{Na}_{2} \mathrm{~S}$, where acetate salts were employed in the synthesis without TAA (bands at 1560 and $1430 \mathrm{~cm}^{-1}$, not reported). The presence of acetamide molecules resulting from the hydrolysis of TAA [58] is less evident, since it should be characterized by the typical amide I band $(\nu \mathrm{CO})$, which is expected with high intensity around $1690-1694 \mathrm{~cm}^{-1}[56]$.

After hot water treatment (sample $\mathrm{ZnS} \_6 \mathrm{~h} \_\mathrm{HW}$, curve b) most of the bands related to TAA $\left(v \mathrm{~S}-\mathrm{H}, \bar{\delta} \mathrm{CH}_{3}-\mathrm{S}, v \mathrm{C}-\mathrm{S}\right)$ disappear, in agreement with TG analysis. What is observed in this case is a broad adsorption in the $v \mathrm{OH}$ region (3 600-2 $500 \mathrm{~cm}^{-1}$ ) suggesting the presence of $\mathrm{OH}$ groups involved in hydrogen bonding. This is confirmed by the observation of a broad band centered at $884 \mathrm{~cm}^{-1}$, related to the corresponding $\delta \mathrm{OH}$. This could be related to partial surface hydroxylation ( $\mathrm{Zn}-\mathrm{OH}$ groups) and water molecules strongly adsorbed on the surface (not removed by RT outgassing), in agreement with the relatively high affinity for water indicated by TGA. The typical $\delta \mathrm{OH}$ mode of $\mathrm{H}_{2} \mathrm{O}$, expected around $1620-1640 \mathrm{~cm}^{-1}$ is observable as a shoulder on the tail of the intense band at $1564 \mathrm{~cm}^{-1}$.

Apart from the bands described above, the main features of sample ZnS_6h_HW are two intense and well defined bands at 1564 and $1441 \mathrm{~cm}^{-1}$, with weaker components at 1348 and $1027 \mathrm{~cm}^{-1}$, which could be mainly assigned to adsorbed acetate groups (the typical amide I band of acetamide, expected around $1690 \mathrm{~cm}^{-1}$ is missing). The interaction energy of these species with the ZnS NP surface is clearly high, since they are not removed after treatment at $573 \mathrm{~K}$ in air (curve c). In this case however, the bands related to $\mathrm{OH}$ groups in hydrogen bonding decreases, in agreement with TG analysis.

Finally, an almost totally cleaned surface is obtained only by thermally activating the sample in vacuum at $673 \mathrm{~K}$. In this case, as already pointed out in Reference [29], only small amounts of acetate bands are observed, which could correspond to the weight loss of step II in TG curves (residual amount of $0.4 \mathrm{wt} \%$, Tab. 2) and could be adsorbed on defective sites or polar surfaces of the material [29].

\subsubsection{DFT Modeling}

DFT modeling has been employed to understand the surface characteristics of the ZnS NP. The surface energies $E_{s}$ of the lowest index ZnS surfaces, the (110), (111) and (100) are $0.6,1.0$ and $1.7 \mathrm{~J} / \mathrm{m}^{2}$, [29]. Dehydroxylated and "clean" surfaces were considered, which should model the situation corresponding to sample $\mathrm{ZnS}$ 673_V, that is of a sample activated in vacuum, with only a small fraction of reactancts adsorbed on reactive surfaces [29]. The size dependence of $E_{s}$ for the (110) and (111) surfaces is reported in Figure 5

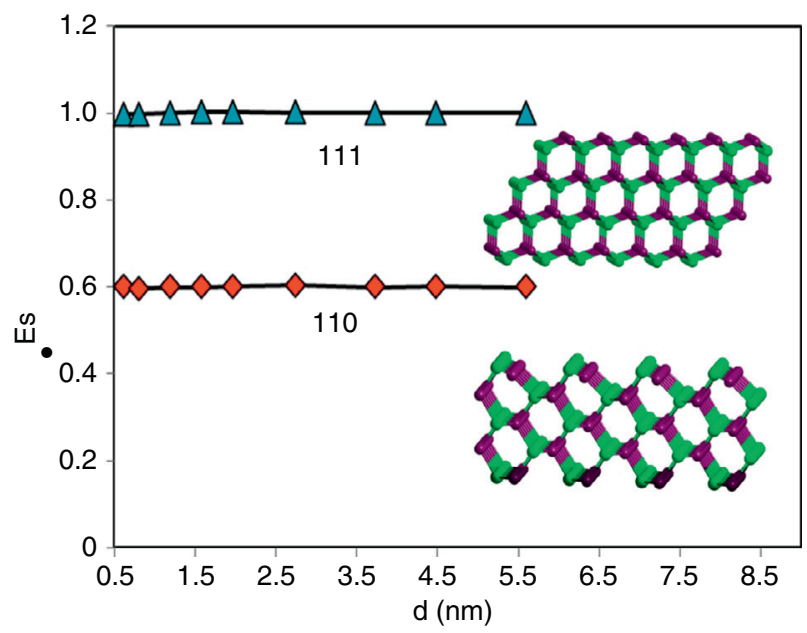

Figure 5

Surface energies $E_{s}$ (in $\mathrm{J} / \mathrm{m}^{2}$ ) of the 110 and $111 \mathrm{ZnS}$ surfaces as a function of the size $d$ of the $\mathrm{ZnS}$ nanoparticles. Results from B3PW calculations.

(hereafter the 100 surface will be not considered anymore because of its very large $E_{s}$ ). Data reported in the figure, collected for $d$ ranging from 0.5 to $6 \mathrm{~nm}$, show that, in $\mathrm{ZnS}$ nanoparticles, the size of the particles does not affect the surface stability. The (110) surface is by far the most stable surface in nanocrystals as it is in microcrystal $[55,59]$. The large differences of the surface energies of the (110) and (111) surfaces is related to their geometrical structure. According to Tasker's electrostatic model [60], in zincblende systems only the (110) surface is non polar, whereas (111) and (100) are polar surfaces of type III. Polar surfaces are characterized by two not equivalent layers of opposite charged ions that alternate along the normal to the surface; each repeat unit bears a dipole moment that increases with the number of the layers and determines the larger instability of these surfaces. Considering the large difference in $E_{s}$ between the two surfaces, the (111) polar one is not likely to be exposed at the $\mathrm{ZnS}$ nanoparticles to a sizable extent, regardless of their size, Figure 5.

In order to shed light on the whole scenario laid out by infrared and TGA, suggesting the presence of a small fraction of strongly adsorbed species, the interaction with the (111) and (110) surfaces of formic acid has been considered. This molecule was employed as a simplified model to represent the acetate species present in solution during the synthesis, which are supposed to be the main species adsorbed on the dehydrated and cleaned $\mathrm{ZnS}$ surface on the basis of infrared spectroscopy. Adsorbed species are schematically depicted in Figure 6 and their main adsorption features collected in Table 3. On the (110) surface one dissociative 
(110) ND1

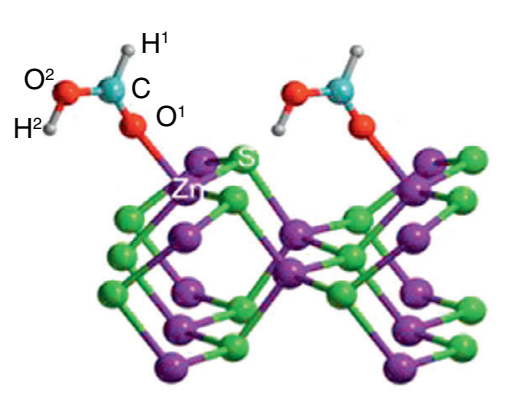

(110) ND2

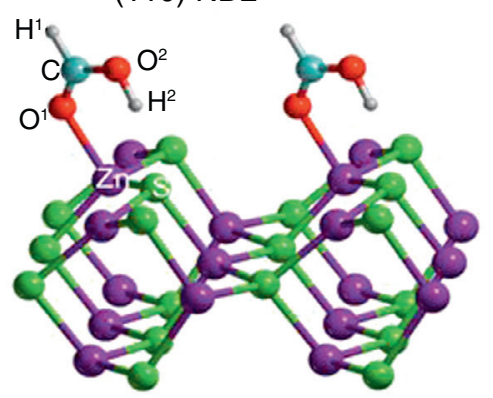

(110) D
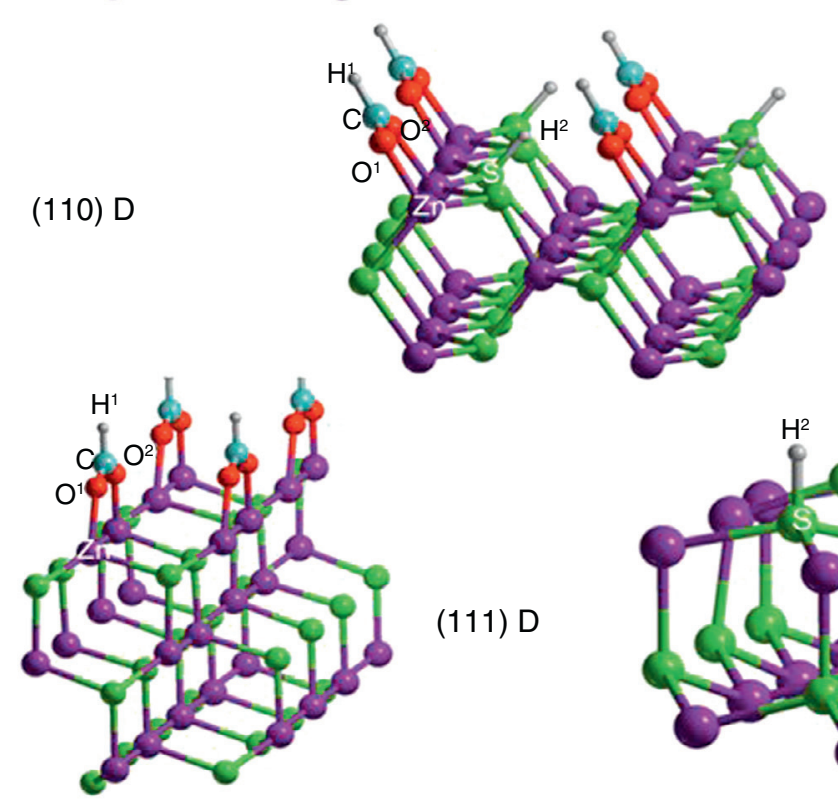

(111) D

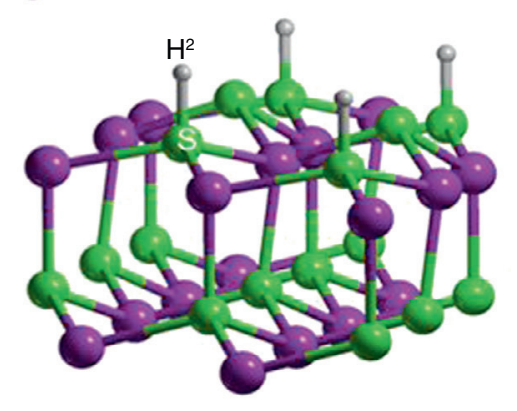

Figure 6

Schematic representation of adsorbed configuration of formic acid on the ZnS (110) and (111) surfaces. Results from PBE0 calculations.

(110-D) and two non dissociative (110-ND1 and 110-ND2) adsorption mode have been considered; only the dissociative adsorption mode can be conceived for the (111) surface (111-D): in this case, the formiate group has been adsorbed on the $\mathrm{Zn}$ terminated surface and the proton on the $\mathrm{S}$ terminated one. At the (110) surface, 110-ND1 is preferred over 110 -ND2 by about $0.04 \mathrm{eV}$ and over 110-D by almost $0.2 \mathrm{eV}$. The 111-D configuration is twice more stable than $110-\mathrm{ND} 1\left(E_{a d s}=2.3 \mathrm{eV}\right)$, Table 3. Computed vibrational frequencies provide a fingerprint for the recognition of the adsorbed species, Table 3. For the 110-ND1 carboxylic group, the asymmetric stretching $v_{\text {as }}(\mathrm{O}-\mathrm{C}-\mathrm{O})=1700 \mathrm{~cm}^{-1}$ and the bending $\delta(\mathrm{C}-\mathrm{OH})=1237 \mathrm{~cm}^{-1}$ are found, while for the 111-D carboxylate group the asymmetric stretching $v_{\text {as }}(\mathrm{O}-\mathrm{C}-\mathrm{O})=1570 \mathrm{~cm}^{-1}$ is indeed shifted to lower wavenumbers with respect to the undissociated form. Only this latter vibration, the asymmetric stretching of dissociate formiate species, is compatible with FTIR data recorded upon the thermal treatment at $573 \mathrm{~K}$ (the peak at $1564 \mathrm{~cm}^{-1}$, Fig. 4c). The significant reduction of this peak only for treatment at very high $T$ (Fig. 4d) indicates an irreversible character of the adsorption, in agreement with the strong computed adsorption energy for 111-D. This finding suggests the presence in the ZnS NP of small extension of the (111) polar surface stabilized by the adsorption of foreign species from the synthesis solution. To this extent, it is worth mentioning a recent report that combining FTIR observations and DFT calculations, has investigated the adsorption properties of $\mathrm{CO}$ molecules, used as a probe for acidic Lewis surface sites; this study has demonstrated that $\mathrm{CO}$ experienced only one type of sites belonging to the (110) surface [29].

The results discussed in the present work, confirm the finding that $\mathrm{ZnS}$ nanoparticles, regardless of their size, expose to a largely wider extent the most stable (110) surface; 
TABLE 3

Main features of the formic acid interaction with the $\mathrm{ZnS}$ (110) and (111) surfaces (PBE0 results). Distances, $d$, in $\AA$; adsorption energies, $E_{a d s}$ in $\mathrm{eV}$, vibrational frequencies $\left(v\right.$ is for stretching - as antisymmetric and s symmetric, $\delta_{B}$ bendings and $\delta$ other angle deformations $)$ in $\mathrm{cm}^{-1}$. To facilitate comparison with experiments, frequencies have been scaled by a factor 0.95521 to align the computed $v(\mathrm{C}-\mathrm{H})$ of gas phase formic acid to the corresponding experimental frequency $\left(2943 \mathrm{~cm}^{-1}\right)$. PBE0 results

\begin{tabular}{|c|c|c|c|c|c|}
\hline & 110-ND1 & 110-ND2 & $110-\mathrm{D}$ & 111-D & Formic acid (gas phase) \\
\hline$d(\mathrm{C}=\mathrm{O})$ & 1.21 & 1.22 & 1.26 & 1.25 & 1.19 \\
\hline$d(\mathrm{C}-\mathrm{OH})$ & 1.33 & 1.31 & 1.26 & 1.25 & 1.34 \\
\hline$d(\mathrm{O}-\mathrm{Zn})$ & 2.17 & 2.24 & 2.00 & 2.00 & - \\
\hline$d(\mathrm{C}-\mathrm{C})$ & 7.70 & 7.70 & 7.70 & 7.75 & - \\
\hline$d(\mathrm{~S}-\mathrm{H})$ & 1.98 & 2.13 & 1.35 & 1.35 & - \\
\hline$\Delta E_{a d s}$ & -0.64 & -0.60 & -0.46 & -2.28 & - \\
\hline$v(\mathrm{O}-\mathrm{H})$ & $2957(751)$ & - & - & - & $3612(113)$ \\
\hline$v(\mathrm{C}-\mathrm{H})$ & $2978(22.3)$ & - & $2898(77.0)$ & $2887(161)$ & $2943(93.3)$ \\
\hline$v(\mathrm{~S}-\mathrm{H})$ & - & - & $2503(1.97)$ & $2507(14.0)$ & - \\
\hline \multirow{2}{*}{$v(\mathrm{O}-\mathrm{CO})$} & \multirow{2}{*}{$1702(397)$} & & $1555(1878)^{\text {as }}$ & $1576\left(\begin{array}{ll}1 & 158\end{array}\right)$ & $1761(55.3)$ \\
\hline & & & $1340(111)^{\mathrm{s}}$ & 1359 (49.4) & - \\
\hline$v(\mathrm{C}-\mathrm{OH})$ & $1337(22.5)$ & - & - & - & 1269 \\
\hline$\delta_{B}(\mathrm{C}-\mathrm{H})$ & $1366(70.1)$ & - & $1373(87.1)$ & $1376(33.8)$ & $1347(42.3)$ \\
\hline$\delta_{B}(\mathrm{O}-\mathrm{H})$ & 1214 & & - & - & $1096(34.4)$ \\
\hline$\delta(\mathrm{C}-\mathrm{H})$ & 1037 & - & 1030 & 1056 & 1015 \\
\hline$\delta(\mathrm{O}-\mathrm{H})$ & 903 & - & - & - & 717 \\
\hline$\delta_{B}(\mathrm{O}-\mathrm{C}-\mathrm{O})$ & $653(86.8)$ & - & $731(10.1)$ & 724 (26.9) & 612 \\
\hline
\end{tabular}

nonetheless, the presence of a minor extension of other surfaces cannot be excluded in reasons of electronic and structural reconstruction or because stabilized by adsorbed species [61].

\subsection{Electronic Properties}

The electronic properties of the prepared $\mathrm{ZnS}$ NP samples were investigated by DR UV-Vis spectroscopy (Fig. 7). This is a simple and widespread technique for the estimation of band gap energy $\left(E_{g}\right)$ in semiconductors [34-37, 62, 63], by the measurement of the absorption edge position, through the Tauc plot elaboration (see Experimental for details) $[38,39]$. This parameter is quite important for applications in photocatalysis, and in semiconducting materials is dependent on particle size, due to quantum size effect [34-37, 40, 63]. Notwithstanding the small size of the primary ZnS NP prepared in this work, these cannot be defined as Quantum Dots (QD), since the UV-Vis spectra of the latter are characterized by the presence of discrete bands (described by the position of their maximum) instead of a continuum absorption (defined by its edge position) [37].

The spectrum of as prepared $\mathrm{ZnS}$-6h is characterized by a relatively large $E_{g}$ value $\left(4.22 \mathrm{eV}, \mathrm{Tab}^{-1}\right)$ with respect to the bulk material $(3.68 \mathrm{eV})[40]$ as a result of nanostructuration [34]. On the contrary, longer reaction time and/or hot water washing result in a shift of the edge position towards higher wavelength values. Indeed, the corresponding $E_{g}$ values are close to that of bulk material for most of the other ZnS samples with crystallite size (estimated by XRD peak widths) between 3.4-4.9 $\mathrm{nm}$ (Tab. 1, entries 2-5). Interestingly, a shift to $E_{g}$ values higher with respect to bulk $\mathrm{ZnS}$ are observed after thermal activation, both in air (ZnS_573) or in vacuum (ZnS_673_V). This could be explained by a higher defectivity of the treated samples surface, influencing their electronic structure.

The considerable dependence of $E_{g}$ on the size of the $\mathrm{ZnS}$ nanoparticles is also confirmed by DFT calculations. Figure 8 reports $E_{g}$ as a function of the size of the nanoparticles: NP with $d \geq 4.5-5.5 \mathrm{~nm}$ have an energy gap that is actually as 


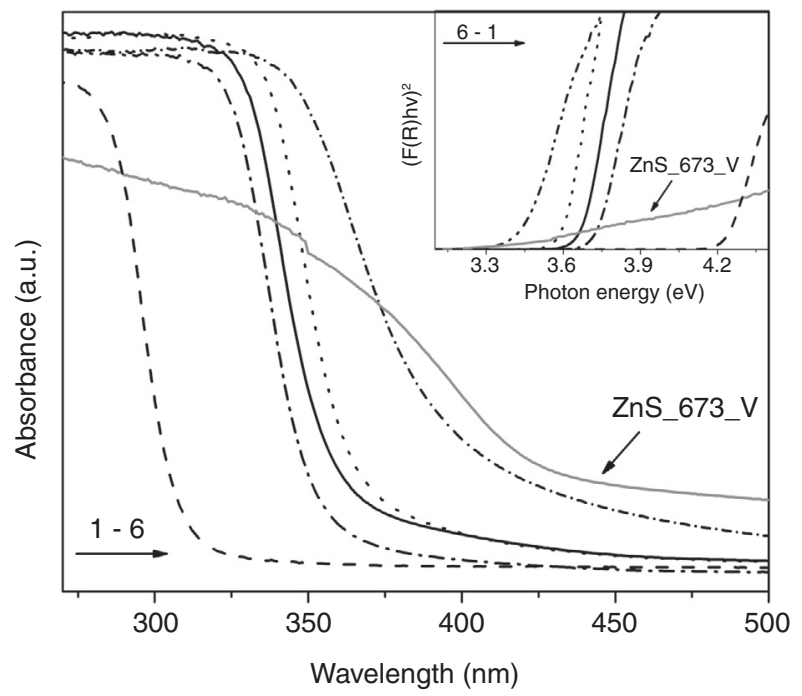

Figure 7

DR UV-Vis spectra of ZnS NP. From left to right: 1) ZnS_6h as such (dashed), 2) ZnS_6h_HW (dot-dashed), 3) ZnS_24h (full), 4) ZnS_24h_HW (dotted), 5) ZnS_573 (short dotdashed), and 6) ZnS_673_V (full grey).

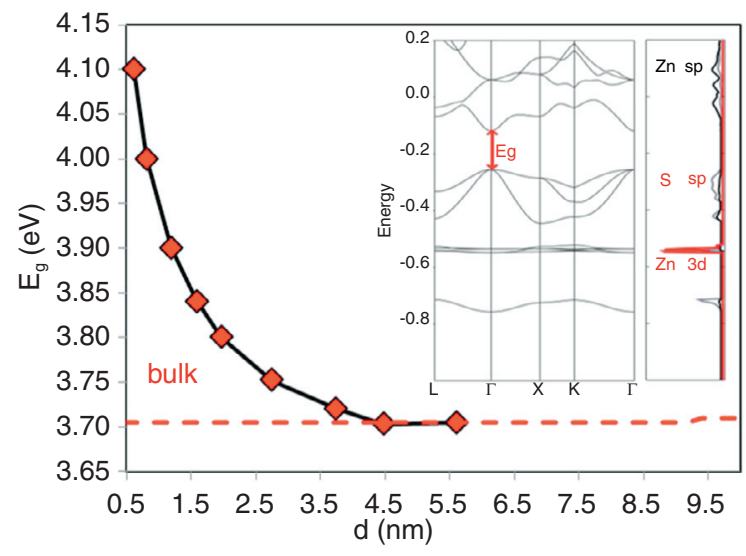

Figure 8

Energy gap, $E_{g}$, as a function of the particle size. The dashed red line is the value for bulk $\mathrm{ZnS}$. In the insert band structure and projected density of states for bulk $\mathrm{ZnS}$. B3PW calculations.

large as the bulk value, $E_{g}=3.7 \mathrm{eV}$, in excellent agreement with observations [40]. In smaller particles, due to quantum size confinement effects, the energy gap increases monotonically by decreasing the size of the NP. For instance $E_{g}=4.1 \mathrm{eV}$ for $d=1.5 \mathrm{~nm}$ and $3.7 \mathrm{eV}$ for $d=5 \mathrm{~nm}$, in very good agreement with XRD estimation (notoriously underestimating particle size) and UV data (Tab. 1). Despite the sensitivity of $E_{g}$ to the size of the NP, the electron structure is almost unaffected by $d$. As reported in the insert of Figure 8, $\mathrm{ZnS}$ is characterized by a direct gap in $\Gamma$ (see also [40]); the top of the valence band is due to $S 3$ sp states and the bottom of the conduction band mainly from $\mathrm{Zn} 3 \mathrm{sp}$ states. The $\mathrm{Zn} 3 \mathrm{~d}$ levels are very deep in energy (about $-15 \mathrm{eV}$ ) and do not contribute to the valence.

\section{CONCLUSIONS}

ZnS NP photocatalysts were prepared by precipitation with TAA and acetate as sulfur and zinc sources, respectively, by modifying reaction time length. The obtained materials were then treated with hot water and thermally, both in air and in vacuum, to remove the reactants adsorbed on the surface of NP during the synthesis. The effect of these procedures on the properties of the $\mathrm{ZnS} \mathrm{NP}$ was studied by combining different techniques and aspects.

The results show that this synthetic methodology allows to prepare nanostructured $\mathrm{ZnS}$ agglomerates, in the form of white powders, with good yield and ease of preparation. Low reaction time $(6 \mathrm{~h})$ resulted in agglomerated crystallites with primary size around $2 \mathrm{~nm}$ (as determined by XRD and TEM). Particle size was found to increase after washing with hot water, as a result of removal of large amounts of adsorbed chemicals. This was also evidenced by thermogravimetric analysis and infrared spectroscopy, indicating the presence of large amounts of TAA (around $18 \mathrm{wt} \%$ ) weakly interacting with the surface. The sample prepared at longer reaction time ( 24 hours) was characterized by larger (around $4 \mathrm{~nm}$ ), more densely aggregated and crystalline $\mathrm{NP}$, which were less sensitive to the treatment with hot water.

Further analysis of the data showed that a small amount of acetate species (around $2 \mathrm{wt} \%$ ) was strongly adsorbed on the ZnS NP surface, and could be removed almost totally only after thermal activation in vacuum at $673 \mathrm{~K}$. This behavior was explained on the basis of DFT calculations, showing the strong adsorption of dissociate formic acid (chosen as a model molecule to simulate the acetate salt employed in the reaction) on the (111) polar surface. This surface is unstable with respect to the apolar (110) one, irrespective to the size of the NP, (Fig. 5), but could be stabilized in a small amount by the adsorption of foreign species from the synthesis solution.

Finally, the electronic properties of the prepared materials were analyzed by DR UV-Vis spectroscopy, by calculating the band gap energy $E_{g}$ with the Tauc plot method. This shows that only the sample prepared at 6 hours reaction (ZnS_6h) without any post-treatment has an $E_{g}$ value sensibly higher with respect to bulk $\mathrm{ZnS}(4.2$ vs $3.7 \mathrm{eV})$, as a result of nanostructuration. When the size of the primary crystallite moves to 3-4 $\mathrm{nm}$ as a result of washing with hot water, longer reaction time or employ of $\mathrm{Na}_{2} \mathrm{~S}$, the band 
gap of the materials corresponds to the bulk one. This trend is rationalized by DFT calculations on $\mathrm{ZnS} \mathrm{NP}$, predicting the modification of the semiconducting electronic structure as a function of particle size.

\section{ACKNOWLEDGMENTS}

Italian Ministry for Research and University (MIUR) is gratefully acknowledged for funding project PRIN 2009BLNJC5 "Optimization of the photothermocatalytic sulfur-ammonia process for hydrogen production". A.M. F. acknowledges CINECA (Iscra project B HOME) for computational resources.

\section{REFERENCES}

1 Honda K., Fujishima A. (1972) Electrochemical Photolysis of Water at a Semiconductor Electrode, Nature 238, 37-38.

2 Kato H., Asakura K., Kudo A. (2003) Highly Efficient Water Splitting into $\mathrm{H}_{2}$ and $\mathrm{O}_{2}$ over Lanthanum-Doped $\mathrm{NaTaO}_{3}$ Photocatalysts with High Crystallinity and Surface Nanostructure, J. Am. Chem. Soc. 125, 10, 3082-3089.

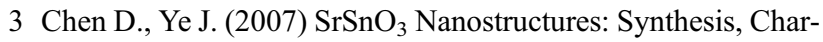
acterization, and Photocatalytic Properties, Chem. Mater. 19, $18,4585-4591$.

4 Domen K., Kudo A., Ohnishi T. (1986) Mechanism of photocatalytic decomposition of water into $\mathrm{H}_{2}$ and $\mathrm{O}_{2}$ over NiO$\mathrm{SrTiO}_{3}$, J. Catal. 102, 92-98.

5 Zou Z., Ye J., Sayama K., Arakawa H. (2001) Direct splitting of water under visible light irradiation with an oxide semiconductor photocatalyst, Nature 414, 625-627.

6 Luo J., Maggard P.A. (2006) Hydrothermal Synthesis and Photocatalytic Activities of $\mathrm{SrTiO}_{3}-$ Coated $\mathrm{Fe}_{2} \mathrm{O}_{3}$ and $\mathrm{BiFeO}_{3}, A d v$. Mater. 18, 4, 514-517.

7 Woodhouse M., Parkinson B.A. (2008) Combinatorial Discovery and Optimization of a Complex Oxide with Water Photoelectrolysis Activity, Chem. Mater. 20, 7, 2495-2502.

8 Bao N., Shen L., Takata T., Domen K. (2008) Self-Templated Synthesis of Nanoporous CdS Nanostructures for Highly Efficient Photocatalytic Hydrogen Production under Visible Light, Chemistry Materials 20, 1, 110-117.

9 Jing D., Guo L. (2006) A Novel Method for the Preparation of a Highly Stable and Active CdS Photocatalyst with a Special Surface Nanostructure, J. Phys. Chem. B 110, 23, 11139-11145.

10 Reber J.-F., Meier K. (1984) Photochemical production of hydrogen with zinc sulphide suspensions, J. Phys. Chem. 88, 5903-5913.

11 Kudo A., Tsuji I., Kato H. (2002) AgInZn7S9 solid solution photocatalyst for $\mathrm{H}-2$ evolution from aqueous solutions under visible light irradiation, Chem. Commun. 17, 1958-1959.

12 Kudo A., Niishiro R., Iwase A., Kato H. (2007) Effects of doping of metal cations on morphology, activity, and visible light response of photocatalysts, Chem. Phys. 339, 1-3, 104-110.

13 Kudo A., Miseki Y. (2009) Heterogeneous photocatalyst materials for water splitting, Chem. Soc. Rev. 38, 1, 253-278.
14 Rockenberger J., Troger L., Kornowski A., Vossmeyer T., Eychmuller A., Feldhaus J., Weller H. (1997) EXAFS studies on the size dependence of structural and dynamic properties of CdS nanoparticles, J. Phys. Chem. B 101, 14, 2691-2701.

15 Nosaka Y., Shigeno H., Ikeuchi T. (1995) Formation of polynuclear cadmium-thiolate complexes and cds clusters in aqueoussolution studied by means of stopped-flow and NMR spectroscopies, J. Phys. Chem. 99, 20, 8317-8322.

16 Vogel W., Borse P.H., Deshmukh N., Kulkarni S.K. (2000) Structure and stability of monodisperse $1.4-\mathrm{nm} \mathrm{ZnS}$ particles stabilized by mercaptoethanol, Langmuir 16, 4, 2032-2037.

17 Kortan A.R., Hull R., Opila R.L., Bawendi M.G., Steigerward M.L., Carroll P.J., Brus L.E. (1984) J. Am. Chem. Soc. 106, 6285-6295.

18 Dance I.G., Choy A., Scudder M.L. (1984) Syntheses, properties, and molecular and crystal structures of $(\mathrm{Me} 4 \mathrm{~N}) 4[\mathrm{E} 4 \mathrm{M} 10(\mathrm{SPh}) 16](\mathrm{E}=$ sulfur or selenium; $\mathrm{M}=$ zinc or cadmium): molecular supertetrahedral fragments of the cubic metal chalcogenide lattice, J. Am. Chem. Soc. 106, 21, 11.

19 Mokili B., Charreire Y., Cortes R., Lincot D. (1996) Thin Solid Films 288, 21-28.

20 Kortan A.R., Hull R., Opila R.L., Bawendi M.G., Steigerwald M.L., Carroll P.J., Brus L.E. (1990) Nucleation and growth of $\mathrm{CdSe}$ on $\mathrm{ZnS}$ quantum crystallite seeds, and vice versa, in inverse micelle media, J. Am. Chem. Soc. 112, 4, 1327-1332.

21 Calandra P., Longo A., Liveri V.T. (2003) Synthesis of ultrasmall $\mathrm{ZnS}$ nanoparticles by solid-solid reaction in the confined space of AOT reversed micelles, J. Phys. Chem. B 107, 1, 25-30.

22 Meneau F., Sankar G., Morgante N., Winter R., Catlow C.R.A., Greaves G.N., Thomas J.M. (2003) Following the formation of nanometer-sized clusters by time-resolved SAXS and EXAFS techniques, Faraday Discuss. 122, 203-210.

23 Meneau F., Cristol S., Sankar G., Dolbnya I.P., Bras W., Catlow C.R.A., Thomas J.M., Greaves G.N. (2003) In situ study of the formation of CdS nanoparticles by small-angle X-ray scattering, J. Appl. Crystallogr. 36, 718-721.

24 Celikkaya A., Mufit A. (1990) Preparation and mechanism of formation of spherical submicrometer zinc sulfide powders, J. Am. Ceram. Soc. 65, 198329, 2360-2365.

25 Liu G., Zhao L., Ma L., Guo L. (2008) Photocatalytic $\mathrm{H}_{2}$ evolution under visible light irradiation on a novel $\mathrm{Cd}_{\mathrm{x}} \mathrm{Cu}_{\mathrm{y}} \mathrm{Zn}_{1-\mathrm{x}-\mathrm{y}} \mathrm{S}$ catalyst, Catal. Commun. 9, 5.

26 Karar N. (2007) Photoluminescence from doped ZnS nanostructures, Solid State Commun. 142, 4.

27 Gruy F., Mekki-Berrada M.K., Cournil M. (2009) Precipitation dynamics of zinc sulfide multi-scale agglomerates, AlChE J. 55, 10,10 .

28 Berlier G., Meneau F., Sankar G., Catlow C.R.A., Thomas J.M., Spliethoff B., Schueth F., Coluccia S. (2006) Synthesis and characterisation of small $\mathrm{ZnS}$ particles, Res. Chem. Intermed. 32, 7, 683-693.

29 Balantseva E., Berlier G., Camino B., Lessio M., Ferrari A.M. (2014) Surface Properties of ZnS Nanoparticles: A Combined DFT and Experimental Study, J. Phys. Chem. C 118, 41, 23853-23862.

30 Monshi A., Foroughi M.R., Monshi M.R. (2012) Modified Scherrer Equation to Estimate More Accurately World NanoCrystallite Size Using XRD, Journal of Nano Science and Engineering 2, 154-160. 
31 Brunauer S., Emmet P.H., Teller E. (1938) Adsorption of Gases in Multimolecular Layers, J. Am. Chem. Soc. 60, 309-319.

32 Barret E.P., Joyner L.G., Halenda P.P. (1951) The Determination of Pore Volume and Area Distributions in Porous Substances. I. Computations from Nitrogen Isotherms, J. Am. Chem. Soc. 73, 1, 373-380.

33 Webb P.A., Orr C. (1997) Analytical Methods in Fine Particle Technology, Micromeritics Instrument Corp, Norcross, GA, USA.

34 Weller H. (1993) Colloidal Semiconductor Q-Particles Chemistry in the Transition Region between Solid-State and Molecules, Angew. Chem. Int. Ed. 32, 1, 41-53.

35 Brus L.E. (1984) Electron-electron and electron-hole interactions in small semiconductor crystallites: The size dependence of the lowest excited electronic state, J. Chem. Phys. 80, 9, 4403.

36 Calandra P., Goffredi M., Liveri V.T. (1999) Study of the growth of $\mathrm{ZnS}$ nanoparticles in water/AOT/n-heptane microemulsions by UV-absorption spectroscopy, Colloid Surf. A 160, 1, 9-13.

37 Manyar H.G., Iliade P., Bertinetti L., Coluccia S., Berlier G. (2011) Structural and spectroscopic investigation of $\mathrm{ZnS}$ nanoparticles grown in quaternary reverse micelles, J. Colloid Interface Sci. 354, 2, 511-516.

38 Grozdanov I., Najdoski M. (1995) Optical and electricalproperties of copper sulfide films of variable composition, J. Solid State Chem. 1142, 469-475.

39 Saravanan R.S.S., Pukazhselvan D., Mahadevan C.K. (2012) Studies on the synthesis of cubic $\mathrm{ZnS}$ quantum dots, capping and optical-electrical characteristics, J. Alloys Compd. 517, 139-148.

40 Amirtharaj P.M., Seiler D.G. (2009) Optical properties of semiconductors, in Handbook of Optics, McGraw Hill, New York, NY.

41 Dovesi R., Saunders V.R., Roetti C., Orlando R., ZicovichWilson C.M., Pascale F., Civalleri B., Doll K., Harrison N.M., Bush I.J., et al. CRYSTAL09 User's Manual, University of Torino.

42 Becke A.D. (1988) Density-functional exchange-energy approximation with correct asymptotic-behavior, Phys. Rev. A 38, 6, 3098-3100.

43 Perdew J.P., Wang Y. (1992) Accurate and simple analytic representation of the electron-gas correlation-energy, Phys. Rev. B 45, 23, 13244-13249.

44 Adamo C., Barone V. (1999) J. Chem. Phys. 110, 6158-6170.

45 Stevens W.J., Krauss M., Bash H., Jaisen P.G. (1992) Can. J. Chem. 70, 612-630.

46 Mino L., Ferrari A.M., Lacivita V., Spoto G., Bordiga S., Zecchina A. (2011) CO Adsorption on Anatase Nanocrystals: A Combined Experimental and Periodic DFT Study, J. Phys. Chem. C 115, 15, 7694-7700.

47 Mino L., Spoto G., Ferrari A.M. (2014) $\mathrm{CO}_{2}$ Capture by $\mathrm{TiO}_{2}$ Anatase Surfaces: A Combined DFT and FTIR Study, J. Phys. Chem. C 118, 43, 25016-25026.
48 Hamad S., Catlow C.R.A. (2006) Computational study of the relative stabilities of $\mathrm{ZnS}$ clusters, for sizes between 1 and 4 nm, J. Cryst. Growth 294, 1, 2-8.

49 Hamad S., Catlow C.R.A., Spano E., Matxain J.M., Ugalde J.M. (2005) Structure and properties of $\mathrm{ZnS}$ nanoclusters, J. Phys. Chem. B 109, 7, 2703-2709.

50 Hamad S., Cristol S., Catlow C.R.A. (2005) Simulation of the embryonic stage of $\mathrm{ZnS}$ formation from aqueous solution, J. Am. Chem. Soc. 127, 8, 2580-2590.

51 Hamad S., Woodley S.M., Catlow C.R.A. (2009) Experimental and computational studies of $\mathrm{ZnS}$ nanostructures, Mol. Simul. 35, 12-13, 1015-1032.

52 Boys S.F., Bernardi F. (1970) The calculation of small molecular interaction by the difference of separate total energies. Some procedures with reduced errors, Mol. Phys. 19, 553-566.

53 Murugadoss G. (2011) Synthesis, optical, structural and thermal characterization of $\mathrm{Mn}^{2+}$ doped $\mathrm{ZnS}$ nanoparticles using reverse micelle method, J. Lumin. 131, 10, 2216-2223.

54 Wang L., Zhao C., Meng F., Huang S., Yuan X., Xu X., Yang Z., Yang H. (2010) Optical properties and simultaneous synthesis of $\mathrm{ZnS}$ and $\mathrm{ZnO}$ nanoparticles via one reverse micellar system, Colloid Surf. A 360, 1-3, 205-209.

55 Emin S., Lisjak D., Pitcher M., Valant M. (2013) Structural and morphological transformations of textural porous zinc sulfide microspheres, Microporous Mesoporous Mater. 165, 185-192.

56 Socrates G. (2006) Infrared and Raman characteristic group frequencies, John Wiley \& Sons Ltd, Chichester, England.

57 Rosenthal D., Taylor T.I. (1957) A Study of the Mechanism and Kinetics of the Thioacetamide Hydrolysis Reaction, J. Am. Chem. Soc. 79, 11, 2684-2690.

58 Gunning H.E. (1955) Thioacetamide as a Sulfide Presipitant in Qualitative and Quantitative Analysis, J. Chem. Educ. 32, 5, 258-259.

59 Siriwardane R.V., Woodruff S. (1997) In situ Fourier transform infrared characterization of sulfur species resulting from the reaction of water vapor and oxygen with zinc sulfide, Ind. Eng. Chem. Res. 36, 12, 5277-5281.

60 Tasker P.W. (1979) J. Phys. Chem. 12, 4977.

61 Goniakowski J., Finocchi F., Noguera C. (2008) Polarity of oxide surfaces and nanostructures, Rep. Prog. Phys. 71, 016501 .

62 Alivisatos A.P. (1996) Semiconductor clusters, nanocrystals, and quantum dots, Science 271, 5251, 933-937.

63 Brus L. (1986) Electronic Wave Functions in Semiconductor Clusters: Experiment and Theory, J. Phys. Chem. 90, 2255-2560.

Cite this article as: E. Balantseva, B. Camino, A.M. Ferrari and G. Berlier (2015). Effect of Post-Synthesis Treatments on the Properties of ZnS Nanoparticles: An Experimental and Computational Study, Oil Gas Sci. Technol 70, 5, 817-829. 